\title{
An Old Method for Good New Cells
}

\author{
G. Damiano, M.C. Gioviale, C. Lombardo, and A.I. Lo Monte
}

\begin{abstract}
The aim of this work was to demonstrate a greater number of viable cells using a micro-surgical in-situ perfusion to collect rat pancreata compared with the pancreas after exsanguination. We used 3 groups of 20 rats. Perfusion was performed by selective cannulation of the left common iliac artery with administration of UW solution at $4^{\circ} \mathrm{C}$. Collected pancreata were digested and cells separated by Ficoll gradient were placed in culture to permit adhesion to dishes. Cells were characterized and tested for viability. We observed a gain of about $14 \%$ in the number of viable cells compared with those obtained after exsanguination $(P<.001$ by chi-square $)$.
\end{abstract}

$\mathbf{W}^{1}$ E SOUGHT to examine whether in situ perfusion as described by Starzl et $\mathrm{al}^{1}$ for cadaver transplants donors could be used to obtain a greater number of stem cells in experimental animal models. This technique has increased the number of potential donors and improved the "biological quality" of the organs by reducing degenerative cellular phenomena induced by ischemia. Starting from this conception, we demonstrated that pancreas collection after in situ perfusion inferred less ischemic damage as confirmed by obtaining a larger quantity and better quality of cells compared with the traditional exsanguination technique.

\section{MATERIALS AND METHODS}

Wistar rats (60 males) of approximately $100 \mathrm{~g}$ were divided into 3 groups: 20 rats were used to improve the collection technique; 20 with pancreas collected after exsanguination; and 20 pancreas collections after in situ perfusion with UW solution ${ }^{2}$ at $4^{\circ} \mathrm{C}$. Animals were fasted for 24 hours before collection to reduce intestinal content. We performed preoperative anesthesia using a wad of ether in the cage to permit easy animal management and then injection of $0.5 \mathrm{cc}$ of droperidol-fentanyl intramuscularly, permitting work for at least 1 hour. Obtaining catatonia (easy to check with the sign of "wire tail"), the animal, which was shaved on the abdomen, was placed supine on a wood tablet. The skin was sterilized with povidone-iodine. Following a xypho-pubic incision, the muscle-aponeurotic plane was exposed by performing an incision along the median line, avoiding damage to the hepatic lobes, which are close to the abdominal wall (Fig 1a). Once the abdominal cavity was opened, a laparotomy was enlarged by small Farabeuf retractors, and the intestine was shifted laterally and enveloped with gauze soaked in warm saline solution. Viscera were gently drawn aside with fingers on their own mesentery and put on gauze, permitting visualization of the kidneys, the silhouette of the cava vein and aorta, the bladder, and the iliopsoas muscle.
The microsurgical phase started with focus setting of the operating microscope to the retro-peritoneal plane of the aorta. Initial phases of aorto-iliac dissection were performed with medium magnification, whereas aorta cannulation was made with maximal magnification. For the delicate skeletization of the aorto-caval plane in the subrenal position we used Castroviejo scissor and jewellery forceps. We tied small lumbar vessels encountered with vascular Graefe curved forceps. We isolated the aorta at the diaphragmatic hiatus level, after shifting the intestine from the upper left side of the laparotomy to the lower left side. Using a Farabeuf retractor, the lateral left and caudate lobes of the liver were shifted above, protected by gauze, and the lesser sac was opened near the lesser curve of the stomach close to the cardia. Aorta is then grabbed with a curve dissection forceps and surrounded with a 0 silk. In the left common iliac artery, which was already prepared with 2 6-0 ligatures, an arteriotomy was performed with Castroviejo scissor, just some millimeters under the iliac crossing, having previously placed a clip on subrenal aorta. The silk 0 was tied. Through the arteriotomy we introduced a 3 -French catheter. The 2 ties were applied to the catheter. After checking the position of the catheter in the aorta under the diaphragm, the clip on subrenal aorta was removed to starts perfusion with UW solution at $4^{\circ} \mathrm{C}$ using a slow, constant pressure on a syringe (Fig 1b). After a few seconds of perfusion, to avoid hypertension of the venous splachnic system, the cava vein was transected under the kidney, causing blood and perfusion solution to flow onto the operative field. Sterile minced ice was added into the abdomen to cool the organs. The whitening of the parenchyma and clear effluent liquid testified to successful perfusion.

From the University of Palermo School of Medicine, Palermo, Italy.

Address reprint requests to Attilio Ignazio Lo Monte, University of Palermo School of Medicine, via del vespro, 129, Palermo 90127, Italy. 


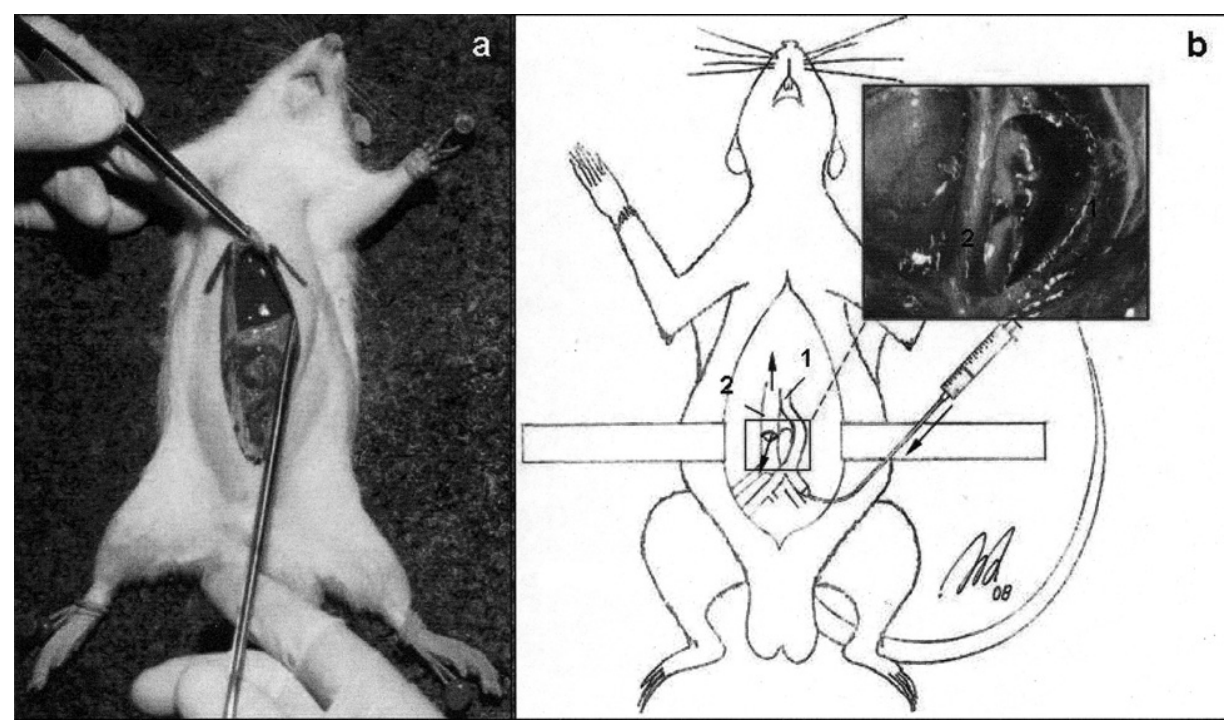

b

Fig 1. Rat pancreas harvesting by microsurgical in situ perfusion technique. (a) Animal placed supine on a wood tablet. Xypho-pubic incision is done by the naked eye. (b) In little square, magnification of microsurgical skeletization of subrenal aorto-caval plane. Aorta (1) cannulation after ligature of small lumbar vessels. Subrenal cava vein (2) section to flow out perfusion solution.
The rat pancreas has no compact aspect, but a characteristic feature is a leaf with small easily distinguishable, tapered lobes. The presence of small clumps on the gland shows trauma during organ collection. It is important to avoid manipulation of the organ. The pancreas must be separated from the spleen. We followed the gland's profile, detaching it from the serosa of the posterior peritoneum plane through blunt dissection of connections to the transverse colon and the duodenal C loop. The last phase consisted of cutting the vascular peduncles (celiac trunk and superior mesenteric artery) to separate the organ from the duodenum with Castroviejo scissors without damage to the wall. The pancreas was saved in a sterile bag with $50 \mathrm{cc}$ of $\mathrm{UW}$ solution at $4^{\circ} \mathrm{C}$ placed in a container with ice and sent to the laboratory.

After collagenase digestion and Ficoll gradient centrifugation, ${ }^{3}$ the residual cell fraction of pancreata was cultured in DMEM media (glucose $5.6 \mathrm{mmol} / \mathrm{L}$ ) with BSA $10 \%$, L-glutamine $2 \mathrm{mmol} / \mathrm{L}$, penicillin/streptomycin $200 \mu \mathrm{L} / \mathrm{mL}$, and fungizone $200 \mu \mathrm{L} / \mathrm{mL}$ for 1 week. Thereafter suspended cells were harvested, while adherent cells were identified using immuno-histochemical staining for CK 19 using mouse monoclonal anti-cytokeratin antibodies (1:50)/goat, anti-mouse immunoglobulin (IgG) FITC (1:250) (Santa Cruz Biotechnology, Calif, United States) as a ductal-cell marker ${ }^{4}$ and DAPI (1:1000). The specimens were mounted cell-side down on glass slides with a drop of DPX for examination using a Zeiss light microscope. Positive cells were randomly counted on the montage of generated photographs. Cell viability was assayed using trypan blue $^{5}$ staining of nonviable cells. Adherent cells were trypsinized and placed on hemocytometer for counting.

\section{RESULTS}

As showed in Figures 2 and 3, we observed that the average number of CK 19-positive cells was 827 on total counting (tc) of $1034(80 \%)$; the number of viable cells was 834 on a tc of $1084(77 \% ; P<.001$ by chi-square).

Among 20 rats that underwent in situ perfusion, we observed an average of 946 CK 19 positive among a tc of $1042(91 \%)$ and 1019 viable cells on a tc of $1120(91 \% ; P<$ .001 by chi-square). The in situ perfusion technique permit- ted us to gain about $14 \%$ of viable cells (Fig 4) compared with the exsanguination technique (Table 1).

\section{DISCUSSION}

We not only were able to perfect a microsurgical procedure, but also to obtain several findings.

The optimal rat weight must be less than $100 \mathrm{~g}$. As a rat grows retroperitoneal fat tissue increases exponentially without a proportional increase in large abdominal vessel diameter. So, a rat less than $100 \mathrm{~g}$ body weight has a retroperitoneal plane that is completely free of fat tissue. A simple evisceration procedure yields iliac vessels that are
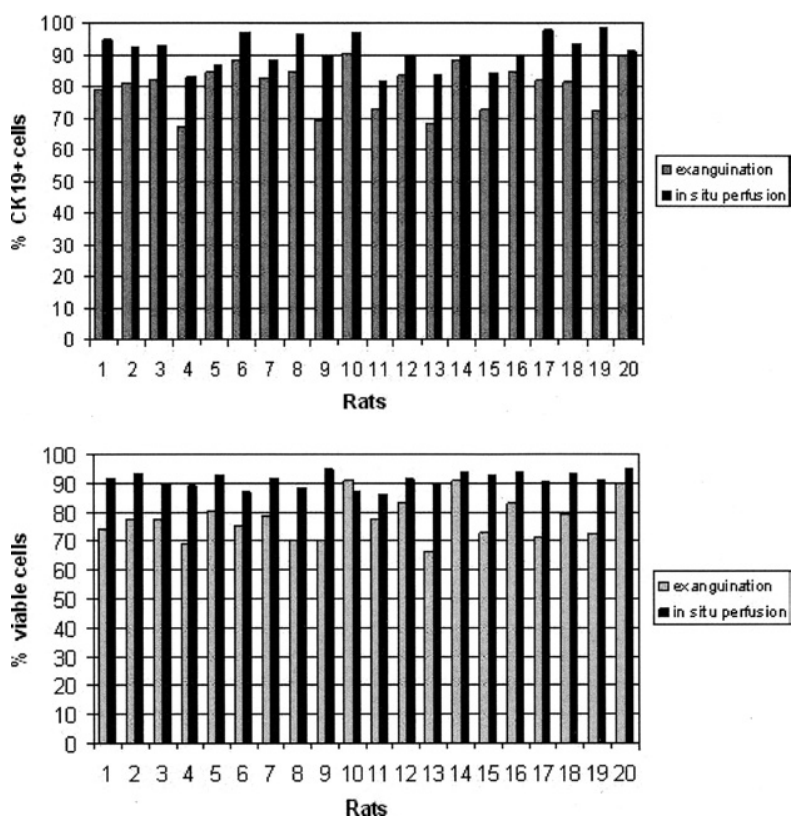

Fig 2. Frequency distribution of $\mathrm{CK} 19+$ and viable cells for each rat. 
Fig 3. Distribution of $\mathrm{CK} 19+$ and viable cells for each rat according to the 2 methods.

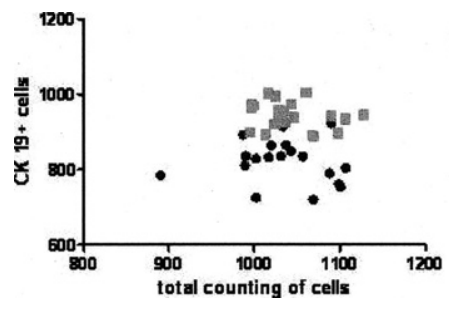

- Exsanguination - Perfusion

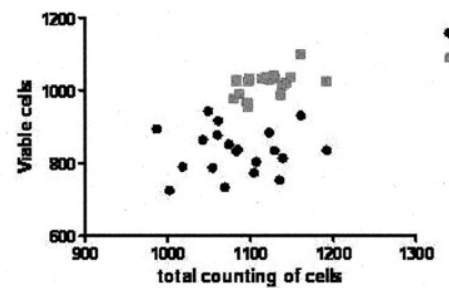

- Exsanguination Perfusion easy to dissect. This is also facilitated because small rats have good surgical cleavage planes in the aorto-caval space.

The best site of aortic cannulation is the proximal common iliac artery. The surgeon must work carefully during the retrieval phases, using the spleen as an anatomical landmark, maintaining traction to not damage the pancreatic tissue with forceps. Adopting the above-mentioned tactics made it possible to retrieve the organ in the best trophic condition avoiding warm ischemia. Therefore, thanks to UW solution at $4^{\circ} \mathrm{C}$ the cells are cold and stabilized, preventing swelling.
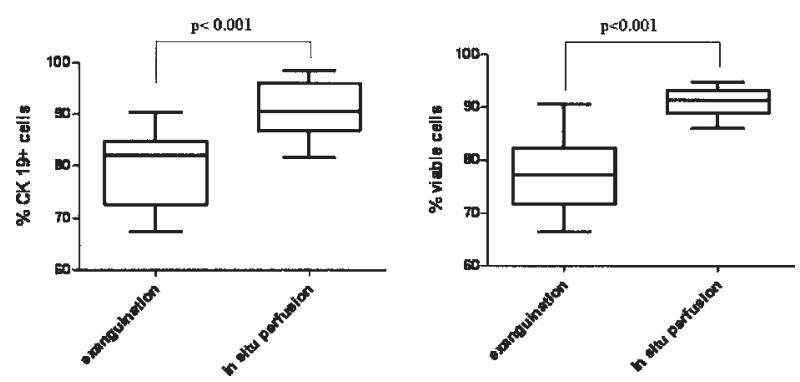

Fig 4. Whisker-and-box plot of percentages of CK19+ and viable cells in the 2 different collection methods.
In conclusion, Delicate manipulation of the pancreas permitted us to obtain a greater number and better quality of viable cells. In light of our results, we believe that this method should be used when a microsurgical work environment (microscope, instruments) is available. Dissection procedures in the aorto-caval plane with ligature of the lumbar vessels offer a good experience to learn essential microsurgical skills. We obtained not only a larger amount of cells, but also a better quality.

\section{REFERENCES}

1. Starzl TE, Hakala TR, Shaw BW Jr, et al: A flexible procedure for multiple cadaveric organ procurement. Surgery Gynecol Obstet 158:223, 1984

2. Belzer FO, Southard JH: Principles of solid-organ preservation by cold storage. Transplantation 45:673, 1988

3. Bonner-Weir S, Taneja M, Weir GC, et al: In vitro cultivation of human islets expanded ductal tissue. Proc Nat Acad Sci 97:7999, 2000

4. Yao ZX, Qin ML, Liu JJ, et al: In vitro cultivation of human fetal pancreatic ductal stem cells and their differentiation into insulin producing cells. World J Gastroenterol 1452, 2004

5. Freshney R: Culture of Animal Cells: A Manual of Basic Technique. New York: Alan R Liss Inc, 1987, p 117

Table 1. Comparison of Quality of Rat Pancreatic Cells Retrieved After Exsanguination and In Situ Perfusion Method*

\begin{tabular}{lcccc}
\hline & Ratio of CK 19-Positive Cells & Percentage of CK19-Positive Cells & Ratio of Viability Cells & Percentage of Viable Cells \\
\hline Exsanguination method & $827 / 1034$ & 80 & $834 / 1084$ & 77 \\
In situ perfusion method & $946 / 1052$ & 92 & $1019 / 1120$ & 91 \\
\hline
\end{tabular}

${ }^{*}$ See text for definitions. 